\title{
Effects of Antihypertensive Drugs on Skin Blood Flow as an Indicator of Sympathetic Responses to Mental Stress in Hypertensive Patients
}

\author{
Hiromi Shinya, Naomi Iwane, Takuzo Hano \\ Medical Education and Population-Based Medicine, Graduate School of Medicine, Wakayama Medical University, Wakayama \\ City, Japan \\ Email: hanotaku@wakayama-med.ac.jp
}

How to cite this paper: Shinya, H., Iwane, N. and Hano, T. (2017) Effects of Antihypertensive Drugs on Skin Blood Flow as an Indicator of Sympathetic Responses to Mental Stress in Hypertensive Patients. Health, 9, 568-575.

https://doi.org/10.4236/health.2017.93040

Received: February 12, 2017

Accepted: March 28, 2017

Published: March 31, 2017

Copyright $\odot 2017$ by authors and Scientific Research Publishing Inc. This work is licensed under the Creative Commons Attribution International License (CC BY 4.0).

http://creativecommons.org/licenses/by/4.0/

\begin{abstract}
The aim of this study was to clarify the response of sympathetic activity to antihypertensive drugs using a mental stress test in hypertensive patients and to determine the effects of antihypertensive drugs on the sympathetic activitymediated hemodynamic response to mental stress. Hypertensive patients were divided into three groups according to the type of drug(s) being taken: a calcium antagonist group, an angiotensin II receptor blocker group, and a combination therapy group of calcium antagonists and angiotensin II receptor blockers. The Stroop color-word conflict test was applied as a mental stress test and hemodynamic responses to mental stress were measured, including blood pressure, pulse rate, and skin blood flow. Elevation of blood pressure by mental stress was suppressed in the combination therapy group compared with the calcium antagonist group. Reduction of skin blood flow by mental stress was suppressed in both the angiotensin II blocker group and the combination therapy group compared with the calcium antagonist group. In conclusion, skin blood flow can be a useful tool to evaluate sympathetic activity and combination therapy with calcium antagonists and angiotensin II receptor blockers were the most useful therapy for suppressing the hemodynamic response to mental stress.
\end{abstract}

\section{Keywords}

Skin Blood Flow, Sympathetic Activity, Calcium Antagonist, Angiotensin II Receptor Blocker, Hypertension

\section{Introduction}

The cause of essential hypertension is multifactorial, with sympathetic tone being one of the important factors. Previous reports have shown that plasma norepi- 
nephrine levels are higher in early and mild hypertensive individual [1]. Plasma catecholamine or plasma 3-methoxy-4-hydroxy-phenylethylene glycol (HMPG) is often used as an index of sympathetic activity. However, sensitive and continuous monitoring of sympathetic activity is difficult [2]. Previous reports have shown that skin blood flow is regulated by sympathetic activity and well reflects sympathetic nerve activity [3] [4] [5].

There are also difficulties in studying the autonomic response to mental stress because the magnitude of the stress is not constant in the mental arithmetic tests and digit recall tasks reported in previous studies. Hoshikawa [6] reported that the Stroop color-word conflict (CWC) test could be useful as an index of mental stress. It causes a steady and reproducible increase in heart rate, systolic blood pressure, and plasma catecholamine.

Two classes of drugs commonly used in Japan are calcium channel blockers (CCBs) and angiotensin II receptor blockers (ARBs). CCBs affect sympathetic activity either directly or by reducing blood pressure. L-type CCBs increase sympathetic activity [7] [8] [9] and ARBs have a potent suppressive effect on sympathetic activity [10] [11]. In the present study, the response of blood pressure, pulse rate [12], and skin blood flow to the CWC test was evaluated to determine the sympathetic response to mental stress in essential hypertensive patients treated with different types of antihypertensive drugs.

\section{Methods and Subjects}

\subsection{Subjects}

Outpatients with essential hypertension treated with CCBs or ARBs at Wakayama Medical University Hospital were enrolled continuously in this study for six month. Finally fifty-two outpatients were enrolled in this study after informed consent. Exclusion criteria were hemodialysis, cerebrovascular disease, aortic aneurysm, myocardial infarction, and color vision disturbance. And untreated hypertensive patients or normal subjects were excluded according with advice of ethical committee. Patients with a pulse rate $>90 / \mathrm{min}$ and those with systolic blood pressure $>160 \mathrm{mmHg}$ at baseline were also excluded. Six subjects were excluded due to systolic blood pressure $>160 \mathrm{mmHg}$ and 4 subjects were excluded due to a lack of blood pressure measurement data. Finally, data from 42 subjects were analyzed. Subjects were divided into three groups of patients, those taking CCBs (CCB group; $n=13$, men/women $7 / 6$, mean age $69.4 \pm 8.5$ years), those taking $\mathrm{ARBs}$ ( $\mathrm{ARB}$ group; $\mathrm{n}=13$, men/women $7 / 6$, mean age $67.7 \pm 8.3$ years), and those taking a combination of both drugs (CCB + ARB group; $n=16$, men/women $6 / 10$, mean age $65.3 \pm 10.3$ years) (Table 1 ).

\subsection{Stroop Color-Word Test}

The CWC test was performed according to Hoshikawa's method [6]. Briefly, the Japanese word for "red", "blue", "green”, "yellow”, or "purple" was shown on a computer display in a random order. The word was written in one of these five colors that was not the actual color of the word shown in the display. At the 
Table 1. Age, height, body weight and body mass index (BMI) of CCB Group, ARB group and CCP + ARB Group.

\begin{tabular}{cccc}
\hline & CCB Group $(\mathrm{n}=13)$ & ARB Group $(\mathrm{n}=13)$ & Ca + ARB Group $(\mathrm{n}=16)$ \\
\hline & $(7$ men, 6 women $)$ & $(7$ men, 6 women $)$ & $(6$ men, 10 women $)$ \\
Age (years) & $69.4 \pm 8.5$ & $67.7 \pm 8.3$ & $65.3 \pm 10.3$ \\
Height $(\mathrm{cm})$ & $157.7 \pm 6.7$ & $161.9 \pm 9.1$ & $157.8 \pm 10.3$ \\
Body weight $(\mathrm{kg})$ & $54.3 \pm 7.7$ & $62.0 \pm 11.4$ & $59.2 \pm 9.8$ \\
BMI & $21.8 \pm 2.3$ & $23.5 \pm 2.6$ & $23.7 \pm 2.9$ \\
& & & Mean $\pm \mathrm{SD}$ \\
\hline
\end{tabular}

same time, another incongruent color name was auditorily given to the subject through headphones. The single color descriptor was presented on the monitor for $2 \mathrm{~s}$. The subject had to push the numeric keybad colored with the same color as the Japanese word shown in the display within $2 \mathrm{~s}$. If the answer was wrong, a loud alarm was given as feedback. These processes were repeated for $10 \mathrm{~min}$.

\subsection{Blood Pressure and Skin Blood Flow Measurement}

Blood pressure and pulse rate were measured using an automatic sphygmomanometer (Omron HEM-907; Kyoto) with the participant in a sitting position 1 min before, every $1 \mathrm{~min}$ during and $1 \mathrm{~min}$ after the mental stress test. The skin blood flow of the fingertip was measured using a laser tissue flow meter (Unique Medical TBF-LN1; Tokyo). Parameters were measured at 2-min intervals for 6 $\mathrm{min}$ at rest, for $10 \mathrm{~min}$ during the mental stress, and for 6 min during the recovery time. Skin flow was recorded continuously through the A/D converter (Power Lab/8sp; ADInstruments) using wave analysis software (Chart v5.4.2; ADInstruments). Because skin blood flow is affected by many factors, including room temperature and respiration rhythmicity, we kept the room temperature and respiration rhythmicity as homogeneous as possible. Blood pressure and pulse rate were measured three times before, five times during, and three times after the mental stress. The average skin blood flow values were calculated for $1 \mathrm{~min}$ and averaged values were sampled three times before, five times during, and three times after the CWC test. Each value was the average of three periods, rest, CWC test, and post-test (Figure 1). The percent changes in their value during the CWC test and in the post-test periods were also calculated from the average value of the rest period.

\subsection{Statistical Analysis}

One-way ANOVA was applied for the comparison of the three averaged values, and two-way ANOVA was used to compare the time course in each group. Values were considered significant at $\mathrm{p}<0.05$.

\subsection{Ethics}

The present study was carried out under the permission of the Ethical Committee 


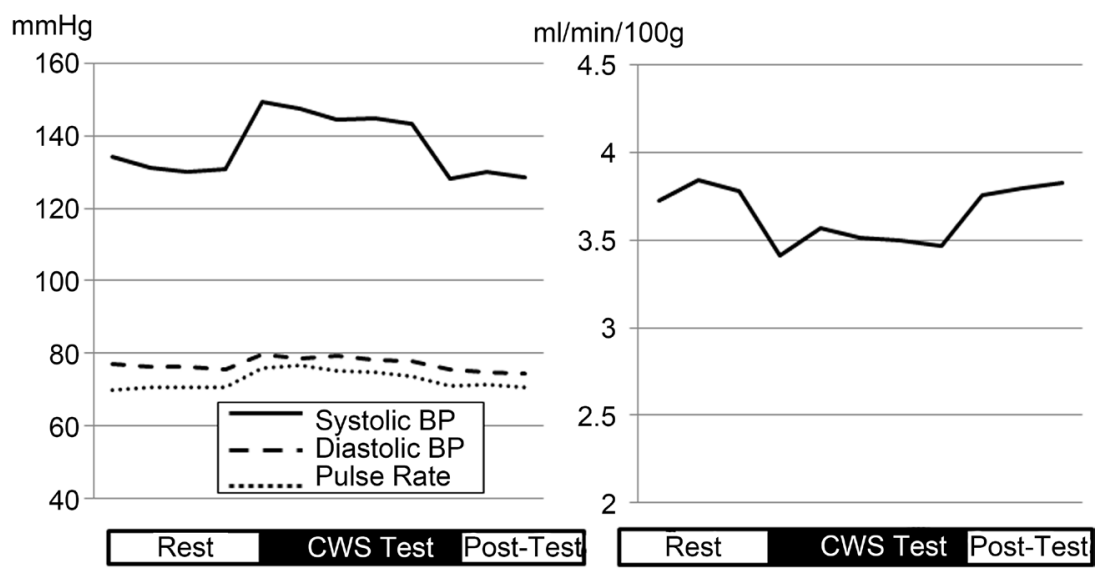

Figure 1. A representative time course example showing blood pressure, pulse rate, and skin blood flow. Systolic and diastolic blood pressure and pulse rate were increased during the CWC test and recovered to baseline after its completion. Skin blood flow was decreased immediately during the CWC test and recovered afterward.

of Wakayama Medical University (\#484). Written informed consent was provided by all participants.

\section{Results}

A representative time course example showing blood pressure, pulse rate, and skin blood flow is shown in Figure 1. Systolic and diastolic blood pressure and pulse rate were increased during the CWC test and recovered to baseline within $1 \mathrm{~min}$ after its completion. The mean systolic blood pressure of the three groups was significantly higher than that of the rest period ( $\mathrm{p}<0.01$ ). Diastolic blood pressure showed a similar trend but the difference was not significant. Pulse rate increased during the CWC test in the CCB $(p=0.002)$ and CCB + ARB $(p<0.01)$ groups but not in the ARB group. Skin blood flow decreased immediately after the CWC test and recovered afterward. The average skin flow during the CWC test was significantly reduced in the CCB $(p=0.024)$ and ARB $(p=0.046)$ groups but not in the CCB + ARB group (Table 2).

The percent change in systolic blood pressure was significantly elevated by the CWC test in the three groups $(\mathrm{p}<0.01)$ and there was no significant difference in the percent change among the three groups. The percent change in diastolic blood pressure was lower in the CCB + ARB group than in the CCB $(p=0.042)$ and ARB ( $\mathrm{p}=0.034$ ) groups (Figure 2$)$.

The percent changes in pulse rate during the CWC test were significantly higher in the $\mathrm{CCB}(\mathrm{p}<0.01)$ and $\mathrm{CCB}+\mathrm{ARB}(\mathrm{p}=0.033)$ groups, but there was no significant change in the ARB group (Figure 3 ). The percent change in pulse rate was significantly lower in the ARB group than in the CCB group ( $p=0.025)$. The percent change in skin blood flow was significantly reduced in the three groups $(\mathrm{p}<0.01)$ and the magnitude of the reduction was significantly different between the CCB group and the ARB $(\mathrm{p}<0.01)$ and $\mathrm{CCB}+\mathrm{ARB}(\mathrm{p}=0.013)$ groups (Figure 3). 
Table 2. Average of the parameters in three groups before, during and after CWS test.

\begin{tabular}{|c|c|c|c|c|}
\hline & & CCB Group & ARB Group & $\mathrm{Ca}+\mathrm{ARB}$ Group \\
\hline \multirow{6}{*}{ Rest } & & $\mathrm{N}=13$ & $N=13$ & $\mathrm{~N}=16$ \\
\hline & Systolic B.P. (mm Hg) & $126.3 \pm 13.1$ & $130.6 \pm 16.8$ & $138.0 \pm 11.9$ \\
\hline & Diastolic B.P. (mmHg) & $72.4 \pm 9.0$ & $76.9 \pm 9.9$ & $79.3 \pm 7.5$ \\
\hline & Pulse rate (/min) & $67.9 \pm 5.6$ & $73.6 \pm 8.9$ & $69.8 \pm 10.1$ \\
\hline & Skin blood flow $(\mathrm{ml} / \mathrm{min} / 100 \mathrm{~g})$ & $3.6 \pm 0.7$ & $4.4 \pm 1.2$ & $3.3 \pm 1.1$ \\
\hline & Systolic B.P. (mmHg) & $138.4 \pm 14.1^{*}$ & $145.0 \pm 20.4^{*}$ & $152.7 \pm 10.6^{*}$ \\
\hline \multirow{2}{*}{ CWS test } & Diastolic B.P. (mmHg) & $76.4 \pm 10.1$ & $80.1 \pm 11.0$ & $79.5 \pm 9.5$ \\
\hline & Pulse rate $(/ \mathrm{min})$ & $73.6 \pm 3.6^{*}$ & $80.1 \pm 11.0$ & $74.4 \pm 9.3^{*}$ \\
\hline \multirow{6}{*}{ Post-test } & Skin blood flow $(\mathrm{ml} / \mathrm{min} / 100 \mathrm{~g})$ & $3.1 \pm 0.8^{*}$ & $4.2 \pm 1.3^{*}$ & $3.2 \pm 1.3$ \\
\hline & Systolic B.P. (mmHg) & $120.0 \pm 9.3$ & $131.0 \pm 14.8$ & $136.3 \pm 13.1$ \\
\hline & Diastolic B.P. (mmHg) & $70.9 \pm 7.3$ & $76.8 \pm 9.2$ & $77.3 \pm 8.8$ \\
\hline & Pulse rate $(/ \mathrm{min})$ & $67.3 \pm 5.3$ & $75.4 \pm 9.3$ & $70.4 \pm 9.9$ \\
\hline & Skin blood flow $(\mathrm{ml} / \mathrm{min} / 100 \mathrm{~g})$ & $3.6 \pm 0.6$ & $4.5 \pm 1.4$ & $3.3 \pm 1.1$ \\
\hline & & & ${ }^{*} \mathrm{p}<0.05$ & $($ Mean \pm SD) \\
\hline
\end{tabular}

*Shows significant difference of value from that at rest. The average systolic blood pressure was increased during CWC test in three groups. The average pulse rate during CWS test in $\mathrm{CCB}$ and $\mathrm{CCB}+\mathrm{ARB}$ group was increased from the value at rest. The average skin blood flow in CCB and ARB group was decreased during CWS test.
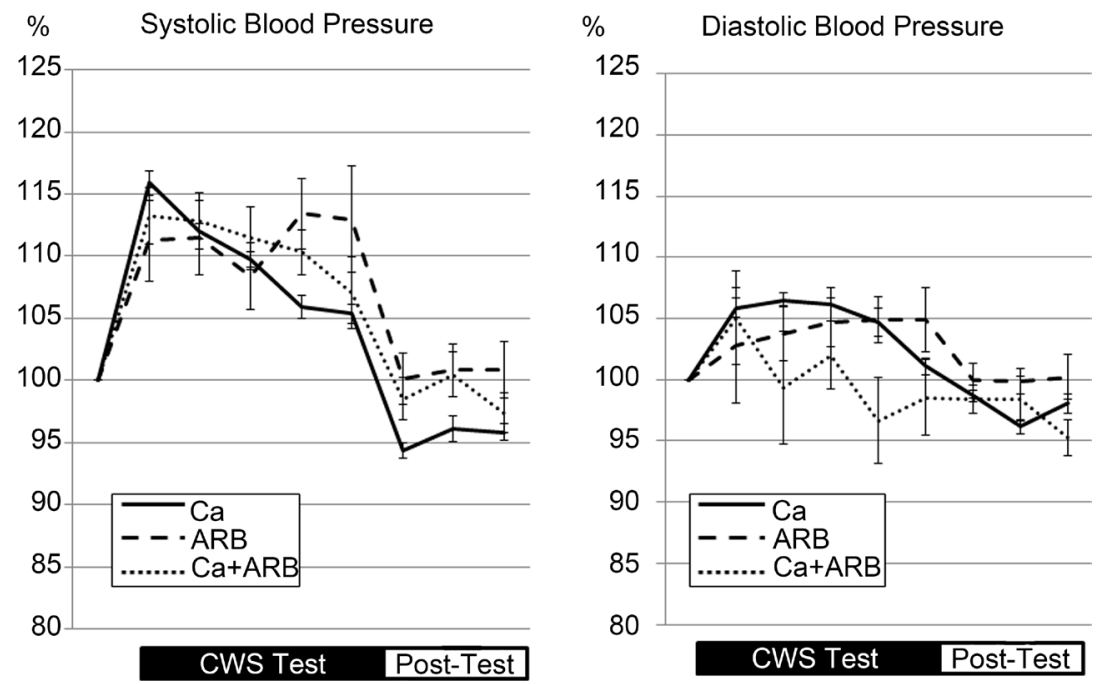

Figure 2. Time curse of systolic blood pressure and diastolic blood pressure in three groups. The percent change in systolic blood pressure was similar in three groups. The percent change in diastolic blood pressure was lower in the $\mathrm{CCB}+\mathrm{ARB}$ group than in the $\mathrm{CCB}$ and ARB groups.

\section{Discussion}

The sympathetic nervous system innervates many organs and plays an important role in the regulation of body fluid and circulation. The circadian rhythm of blood pressure in patients with hypertension is also regulated by sympathetic 

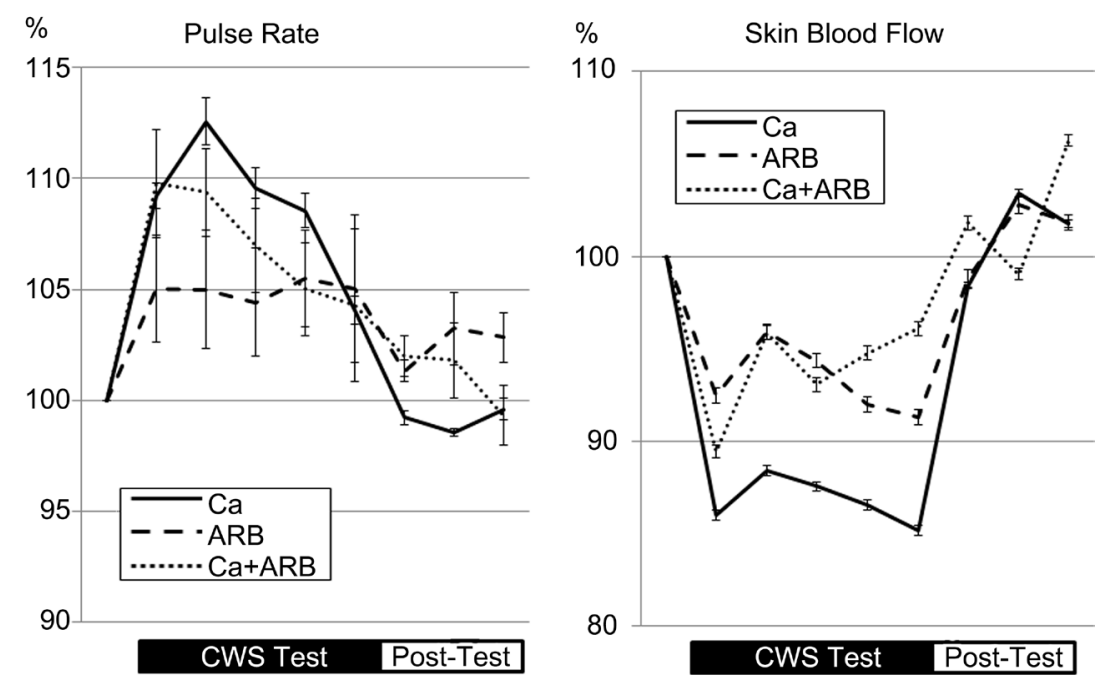

Figure 3. Time course of pulse rate and skin blood flow in three groups. The percent change in pulse rate was significantly lower in the ARB group than in the CCB group. The magnitude of the reduction in skin blood flow was significantly lower in the CCB group than the ARB and CCB + ARB groups.

and parasympathetic activity. Morning surge and blood pressure elevation during mental stress can predict cardiovascular events. In the present study, the CWC test affected blood pressure, heart rate, and skin blood flow. These results indicate the usefulness of the CWC test as a tool for stimulating sympathetic nervous system activity and the measurement of skin blood flow as a sensitive index of sympathetic nerve activity.

The antihypertensive drugs mainly used in clinics are CCBs and ARBs. The dihydropyridine CCB nifedipine sensitizes cardiopulmonary baroreceptors and causes muscle sympathetic nerve activation measured by microneurography in healthy humans [7]. Nifedipine has an excitatory effect and verapamil has an inhibitory effect on the carotid sinus baroreceptor in dogs [8]. The long-acting dihydropyridine CCB amlodipine has no significant effects on plasma norepinephrine levels, muscle sympathetic nerve activity, and baroreflex responses in patients with heart failure [9]. ARBs have potent pharmacological suppressive effects on $\mathrm{AT}_{1}$ receptors at presynaptic sites and suppress neurotransmitter release from nerve terminals. Administration of lisinopril or losartan has no effect on heart rate or splanchnic nerve activity in rats [10]. In a clinical study of ARBs, candesartan suppressed cardiac sympathetic nerve activity in patients with congestive heart failure [11]. We evaluated the effects of mental stress on sympathetic activity in patients treated with CCBs, ARBs, or their combination because combination therapy is increasingly common in the Japanese population. In this study, diastolic blood pressure elevation was more suppressed in the CCB + ARB group than in the CCB group. The change in skin blood flow was more marked in the ARB and $\mathrm{CCB}+\mathrm{ARB}$ groups than in the $\mathrm{CCB}$ group. These data suggest that long-acting calcium antagonists augment sympathetic activation induced by mental stress and that ARBs have less effect on cutaneous sympathetic nerves. Combination therapy has strong sympatho-inhibitory effects on these nerves. 


\section{Conclusion}

In conclusion, skin blood flow is a useful index of sympathetic activity. ARBs or a combination of CCBs and ARBs suppress mental stress-induced sympathetic activity more than calcium antagonists alone.

\section{Acknowledgements}

This study was supported by a Grant-in-Aid for Scientific Research (C) (\#26460915) from the Ministry of Education, Culture, Sports, Science and Technology (MEXT), Japan.

\section{References}

[1] Nishimura, T., Nishio, I., Ohtani, H., Jimbo, S., Kuchii, M. and Masuyama, Y. (1979) Plasma Catecholamines Determination Using High Pressure Liquid Chromatography and Their Roles in Blood Pressure Regulation and Experimental Hypertension in Rats. Japanese Circulation Journal, 43, 855-865. https://doi.org/10.1253/jcj.43.855

[2] Mizukoshi, M., Hano, T., Kuchii, M., Nishio, I. and Masuyama, Y. (1985) Plasma Noradrenaline and Its Deaminated Metabolites in Essential Hypertension and Pheochromocytoma. Japanese Circulation Journal, 49, 1035-1042. https://doi.org/10.1253/jcj.49.1035

[3] Sakuragi, T., Okamoto, I., Fujiki, T. and Dan, K. (1996) Skin Blood Flow and Plasma Catechol Amines during Removal of Pheochromocytoma. Anesthesiology, 85, 1485-1488. https://doi.org/10.1097/00000542-199612000-00032

[4] Yamamoto, K., Sobue, G., Iwase, S., Nagamatsu, M., Mano, T. and Mitsuma, T. (1997) Skin Sympathetic Nerve Activity in Guillain-Barre Syndrome: A Microneurographic Study. Journal of Neurology, Neurosurgery, and Psychiatry, 63, 537-541. https://doi.org/10.1136/jnnp.63.4.537

[5] Koskinen, L.O.D. and Blomstedt, P. (2008) Sympathicotomy Affects Cutaneous Blood Flow, Temperature, and Sympathicus-Mediated Reflexes. Acta Neurologica Scandinavica, 118, 402-406. https://doi.org/10.1111/j.1600-0404.2008.01046.x

[6] Hoshikawa, Y. and Yamamoto, Y. (1997) Effects of Stroop Color-Word Conflict Test on the Autonomic Nervous System Response. American Journal of Physiology, 272, H1113-H1121.

[7] Ferguson, D.W. and Hayes, D.W. (1989) Nifedipine Potentiates Cardiopulmonary Baroreflex Control of Sympathetic Nerve Activity in Healthy Humans. Direct Evidence from Micro Neurographic Studies. Circulation, 80, 285-298. https://doi.org/10.1161/01.CIR.80.2.285

[8] Heesch, C.M., Miller, B.M., Thames, M.D. and Abboud, F.M. (1983) Effects of Calcium Channel Blockers on Isolated Carotid Baroreceptors and Baroreflex. American Journal of Physiology, 245, H653-H661.

[9] Grassi, G., Spaziani, D., Serevalle, G., Bertinieri, G., Dell'Oro, R., Cuspidi, C. and Mancia, G. (1999) Effects of Amlodipine on Sympathetic Nerve Traffic and Baroreflex Control of Circulation in Heart Failure. Hypertension, 33, 671-675. https://doi.org/10.1161/01.HYP.33.2.671

[10] Niederberger, M., Aubert, J., Nussberger, J., Brunner, H.R. and Waeber, B. (1995) Sympathetic Nerve Activity in Conscious Renal Hypertensive Rats Treated with an Angiotensin Converting Enzyme Inhibitor or an Angiotensin II Antagonist. Journal of Hypertension, 13, 439-445. https://doi.org/10.1097/00004872-199504000-00010 
[11] Kasama, S., Toyama, T., Kumakura, H., Takayama, Y., Ichikawa, S., Suzuki, T. and Kurabayashi, M. (2005) Effects of Candesartan on Cardiac Sympathetic Nerve Activity in Patients with Congestive Heart Failure and Preserved Left Ventricular Ejection Fraction. Journal of the American College of Cardiology, 45, 661-667. https://doi.org/10.1016/j.jacc.2004.11.038

[12] Wallin, B.G. and Charkoudian, N. (2007) Sympathetic Neural Control of Integrated Cardiovascular Function: Insights from Measurement of Human Sympathetic Nerve Activity. Muscle Nerve, 36, 595-614. https://doi.org/10.1002/mus.20831

Submit or recommend next manuscript to SCIRP and we will provide best service for you:

Accepting pre-submission inquiries through Email, Facebook, LinkedIn, Twitter, etc. A wide selection of journals (inclusive of 9 subjects, more than 200 journals)

Providing 24-hour high-quality service

User-friendly online submission system

Fair and swift peer-review system

Efficient typesetting and proofreading procedure

Display of the result of downloads and visits, as well as the number of cited articles Maximum dissemination of your research work

Submit your manuscript at: http://papersubmission.scirp.org/

Or contact health@scirp.org 